\title{
DISTINÇÃO ENTRE PROCEDIMENTOS TÉCNICO E LÓGICO NA ANÁLISE FENOMENOLÓGICA
}

\author{
Distinction Between Technical and Logical Procedures on Phenomenological Analysis
}

Distinción entre Procedimientos Técnico y Lógico del Análisis Fenomenológico

William Barbosa Gomes

\begin{abstract}
Resumo: Em 1986, eu utilizei uma estratégia singela para o exercício da lógica da fenomenologia com alunos de graduação. Solicitei a eles que descrevessem como seria uma boa aula para estudantes de psicologia em uma universidade. A pergunta era pertinente diante das instabilidades pedagógicas da época, quando não se tolerava estruturas clássicas de aulas e nem se sabia como articular propostas liberalizantes. Cinco alunos e quatro alunas, entre 18 e 21 anos responderam ao exercício. Vinte anos depois, revendo o material recolhido, fiquei impressionado com a força expressiva dos depoimentos e a oportunidade de diferenciar alguns aspectos procedurais da análise fenomenológica: a distinção entre técnica e lógica. Neste texto, seguindo a fenomenológica triádica de Husserl e de Merleau-Ponty, percorro os dois caminhos de análise, diferenciando procedimentos técnicos (etapas de organização do material) e lógicos (movimento reflexivo entre o dado da experiência e o ato da consciência). A minha conclusão é que a explanação de métodos e materiais não se restrinja aos procedimentos técnicos e organizadores da análise, mas ressalte a articulação entre a lógica da intencionalidade situada e da intencionalidade apropriável.
\end{abstract}

Palavras-chave: Técnica Fenomenológica; Lógica Fenomenológica; Gestalt Radical; Ensino-aprendizagem.

Abstract: In 1986 I used a simple strategy to exercise phenomenological logic with undergraduate students. I asked them to describe how a good class in Psychology would be. The question was relevant due to the pedagogical instabilities of the time. The classical class structures were not tolerated, but it was not clear how to articulate liberal alternatives. The participants were students, with ages between 18 and 21 years old, five males and four females. Twenty years later, after I reviewed the data, I was impressed by the expressiveness strength of those testimonials, and the opportunity to differentiate some procedural aspects of the phenomenological analysis: the distinction between technique and logic. In this paper, I go through two ways of analysis to differentiate technical procedures (i.e. the stages of data organization) from logical procedures (i.e. the reflexive movement between the experience's data and the consciousness' act). First, I will follow Husserl and second Merleau-Ponty. I conclude that the explanation of methods and materials shall not be restricted to the technical and organizing procedures of analysis. It shall remark the articulation between the logics of located and appropriative intentionality.

Keywords: Phenomenological Technique; Phenomenological Logic; Radical Gestalt; Teaching; Learning.

Resumen: En el año de 1986 utilicé una estrategia sencilla con los alumnos del curso de graduación en psicología, para el ejercicio de la lógica de la fenomenología. Les fue solicitado describir como sería una buena clase para alumnos de psicología en una Universidad. La pregunta era pertinente delante de la inestabilidad pedagógica de la época, momento en el cual no eran toleradas las estructuras clásicas en las clases y tampoco sabían como articular propuestas más liberales. Cinco alumnos y cuatro alumnas entre 18 y 21 años, contestaron al ejercicio. Veinte años más tarde, revisando los datos de entonces, me impresionó la fuerza expresiva de los testimonios y la oportunidad de diferenciar algunos aspectos del procedimiento del análisis fenomenológico: la distinción entre técnica y lógica. En este texto, basándome en la fenomenológica triádica de Husserl y de MerleauPonty, sigo los dos caminos del análisis, diferenciando procedimientos técnicos (etapas de organización del material) y lógicos (movimiento reflexivo entre el dato del experimento y el acto de consciencia). La conclusión a que llegué es que la explicación de los métodos y materiales no deben limitarse a los procedimientos técnicos y organizadores del análisis, pero resaltar la articulación entre la lógica de la intencionalidad ubicada y la intencionalidad apropiable.

Palabras-clave: Técnica Fenomenológica; Lógica Fenomenológica; Gestalt Radical; Enseñanza; Aprendizaje.

As pesquisas qualitativas em suas muitas variações e possibilidades têm prestado grande serviço às ciências humanas, sociais e da saúde, permitindo o estudo em profundidade de fenômenos para os quais não se teria acesso de outra maneira. Há quem afirme que a psicologia passou por duas revoluções simultâneas no final do século XX: as ciências cognitivas (Mahoney, 1993) e as pesquisas qualitativas (Nicolaci-da-Costa, 2007). Realmente, a dissemina- ção das pesquisas qualitativas abriu muitas possibilidades de estudo, contribuindo para a elucidação de problemas e de situações não acessíveis por outros métodos.

A extensa literatura dedicada à introdução da pesquisa qualitativa (Denzin \& Lincoln, 2000) concentra-se em torno de fundamentos comuns aos diversos métodos, a saber: a etnografia, a fenomenologia e a semiótica. Com efeito, as várias modalidades de pesquisa qualitativa de- 
correm de um ou outro desses fundamentos ou da combinação ou releitura deles. Propositalmente, tomarei, como justificativa para o meu argumento, exemplos da literatura recente, colocando em suspenso, ao menos nessa introdução ao texto, menção aos autores clássicos. Assim, da etnografia (Creswell, 2007) vem o reconhecimento da importância do contexto e da cultura para decodificação de regras que regulam valores, crenças e comportamentos. São regras próprias à cultura ou ao contexto e que devem ser compreendidas na perspectiva interna e não externa. Da fenomenologia (Moreira, 2002) vem a preocupação com a subjetividade na apropriação do objeto, sendo esta apropriação a relação processual da consciência com a experiência. Há aqui o cuidado de distinguir e diferenciar a consciência enquanto ato e objeto. Tal distinção aponta para a relação entre consciência (sujeito) e experiência (objeto), e para as dificuldades inerentes à ultrapassagem do objeto pelo sujeito (ver o que se quer ver), ou do sujeito pelo objeto (ver sem considerar a perspectiva do olhar). A fenomenologia oferece recursos formais para o pesquisador olhar simultaneamente para o objeto e para si mesmo. Da semiótica (Shank, 1995) temos a noção de que as experiências apresentam-se à consciência na forma de linguagens, com seus sistemas de signos e significações. Os sistemas de signos estão organizados em diferentes níveis estruturais que perpassam a forma do fenômeno, em maior ou menor visibilidade. A semiótica nos oferece os meios para uma compreensão estrutural e Gestáltica da situação que queremos compreender, decodificando e especificando as diferenças intra-níveis e inter-níveis.

Os três fundamentos indicam que os objetos apresentados às pesquisas qualitativas são auto-regulados em contextos, sensíveis às tensões entre o que está se apresentando ao conhecimento e o que já é conhecido, assumindo configurações variadas quanto à forma de expressão e de percepção. Os três fundamentos priorizam o conhecimento de primeira pessoa, mas não desconsideram o olhar objetivo e racional de terceira pessoa, e nem a intersubjetividade da segunda pessoa sem a qual não seria possível a comunicação e, por conseguinte, a pesquisa. Com esses três fundamentos temos uma base sólida para uma pesquisa voltada às qualidades vivenciais que é rigorosa e racional; Gestáltica e sistemática.

O objetivo deste texto é mostrar como procedimentos técnicos se distinguem de procedimentos lógicos, na prática de pesquisa qualitativa. Essa distinção entre técnica e lógica auxilia a realização da análise e contribui para a compreensão conjuntural do problema. Dos três fundamentos é a fenomenologia que trata diretamente da relação entre a compreensão do pesquisador e os dados de pesquisa. Essa relação inclui as implicações concernentes ao procedimento técnico para obtenção e organização dos dados para a análise, e ao procedimento lógico que conduz a análise. Os autores clássicos de referência serão Husserl (1859-1938) e Merleau-Ponty (1908-1961).
A diferença entre procedimentos técnicos e lógicos será ilustrada por materiais recolhidos em um exercício sobre como fazer uma análise fenomenológica.

As considerações apresentadas no presente texto vêm a propósito do sugestivo livro de Daniel Augusto Moreira sobre O Método Fenomenológico na Pesquisa publicado em 2002, com reimpressão em 2004. Temos aí uma indicação concreta de que o interesse pelo método fenomenológico continua vivo. Com a clareza peculiar ao engenheiro, Moreira encontrou um modo inovador e apreciável para introduzir o método. Ele inicia com uma apresentação da ciência formal e factual do velho e bom método experimental, para em seguida introduzir os métodos qualitativos e, entre eles, as características singulares da fenomenologia. Contudo, ao exemplificar diferentes propostas para o método fenomenológico, citando Van Kaam (1959) ${ }^{1}$, Colaizzi (1978), Sanders (1982), e Giorgi (1985), Moreira não diferenciou propriamente procedimentos técnicos de procedimentos lógicos. Em contraste, Giorgi (2006) foi veemente ao listar e discutir teses de doutorados que alegaram orientar-se pelo método fenomenológico husserliano, mas que confundiram ou não distinguiram técnica e lógica.

\section{Distinção entre Procedimentos Técnicos e Lógicos}

Procedimentos técnicos são aqueles que se referem às etapas que orientam a organização do material obtido. Giorgi (1985) especificou quatro procedimentos técnicos para análise: 1) leitura geral do material, 2) definição de unidades de sentido, 3) expressão das unidades na perspectiva escolhida pelo pesquisador, e 4) formulação de uma síntese das unidades ${ }^{2}$. Em contraste, procedimentos lógicos articulam a racionalidade que conduz a análise e focalizam a mediação entre o que é dado como referência e o que é tomado como significado (Lanigan, 1997). O que está sob constante atenção é o papel da mediação, isto é, a unificação do ato e do objeto na consciência. A mediação pode levar a outra mediação e assim sucessivamente, com o risco de se distanciar do referente original.

O método fenomenológico é um movimento entre reflexões com a finalidade de conhecer, definir e compreender um fenômeno circunscrito a um contexto (um modo de relação), como ocorre nas ciências aplicadas; ou um fenômeno em forma absoluta e generalizável (um modo de ser), como ocorre nas ciências básicas. Um aspecto

\footnotetext{
Adrian Van Kaam (1920-2007) foi pioneiro no uso do método fenomenológico para a psicologia. Foi quem introduziu uma maneira de realizar pesquisa empírica em fenomenologia, depois adotada por Amedeo Giorgi. Foi o fundador do Programa de Psicologia Fenomenológica da Duquesne University. Com esta nota, presto homenagem a este grande fenomenólogo que faleceu em 17/11/2007, quando este artigo estava sendo escrito.

2 Ver Giorgi, 1985, p. 10; Moreira 2002, p. 123-124.
} 
interessante dessas reflexões é o movimento triádico entre elas, ou seja, como se movimenta da primeira, para a segunda e daí para a terceira reflexão. O fim de um ciclo abre o início de outro, pois cada reflexão é também triádica e assim sucessivamente. O método fenomenológico distingue-se pela condição de ser abrangente e transparente em seus passos analíticos.

A lógica triádica nos acompanha desde as análises anteriores de Aristóteles, considerada por ele como a argumentação lógica perfeita. Em Aristóteles (Órganon), a tríade era constituída por duas proposições declarativas que se conectavam de tal modo, permitindo que se deduzisse uma conclusão. Em Kant (1977) a tríade aparece em um texto de 1783, sobre a metafísica futura, na elucidativa ordem: percepção, entendimento e razão. A tríade em Peirce é uma redução das categorias transcendentais de Kant, sendo elas: Possibilidade, Existência e Mediação. A Possibilidade é a propriedade relacional que conta apenas com um termo (Primeiridade). A Existência é uma propriedade relacional entre dois termos, ou seja, a relação de interação de um objecto com outro (Secundidade). A Mediação é uma propriedade relacional entre três termos (Terceiridade). Em Husserl (1913/1975, 1933/1977) a reflexividade apresenta-se em três etapas: 1) a epoché fenomenológica, que é o retorno para a experiência imediata, isto é, para o dado que se presenta à consciência como objeto; 2) a redução eidética que transforma a descrição em especificações proposicionais, requerendo o exercício da imaginação livre; e 3) análise transcendental que se constitui na descoberta da intencionalidade, não podendo ser confundida com a tomada de sentido procedente da experiência inicial. Na análise transcendental deverá esclarecer-se o ato que faz a conexão entre a consciência e seus objetos, superando a subjetividade com a intersubjetividade. A intersubjetividade é o compartilhamento de subjetividades fazendo possível a experiência da objetividade. Merleau-Ponty (1945/1994) redefiniu a tríade lógica, trazendo os princípios da fenomenologia ideacional de Husserl para o mundo vivencial, não distinguindo o sujeito do seu corpo e do seu universo. Nessa fenomenologia, a descrição (primeira reflexão) é uma apropriação da realidade do modo que ela é, ou seja, tomar o que é possivel, dada a condição humana de ser um self corporificado com o poder do movimento. A redução (segunda reflexão) concentra-se na distinção entre este self corporificado e o fenômeno que percebe, isto é, o self sendo diferenciado do outro e da coisa percebida. A interpretação (terceira reflexão) é o encontro da intencionalidade que o objeto traz com a intencionalidade do sujeito que se apropria do objeto. Neste ponto, o pesquisador assume uma posição de crítico e de transformador, pois detém um conhecimento privilegiado e está em condições de acionar estratégias de mudanças, se for o caso. Lanigan (1992) traz para a tríade lógica a influência da semiologia de Saussure, redefinindo a dualidade tradicional de significante e significado numa tríade, na qual a descri- ção especifica um discurso comunicativo (signo); a redução extrai aqueles elementos que expresam a essência da descrição (significante); e a interpretação define o que é essencial e revelador no que foi descrito (significado). A preocupação com a seqüência lógica triádica está também em manuais que tratam de aspectos práticos da pesquisa qualitativa. Patton (1990) refere-se à descrição qualitativa, à análise indutiva, e à análise lógica; e Yin (1994) à descrição, ao entendimento e à explicação.

\section{Exercício "Uma Boa Aula de Psicologia?"}

No segundo semestre de 1986, em uma de minhas aulas sobre pesquisa qualitativa no Curso de Psicologia da Universidade Federal do Rio Grande do Sul solicitei aos alunos presentes que respondessem a uma pergunta sobre o tema aula, para em seguida exercitarmos a tríade reflexiva da fenomenologia. A enunciação da tarefa foi a seguinte: "Descreva como seria uma boa aula para estudantes de psicologia numa universidade”. Cinco alunos e quatro alunas, entre 18 e 21 anos responderam ao exercício. A enunciação era ampla e permitia que os participantes seguissem diferentes abordagens em suas respostas. Na época passávamos por grandes instabilidades pedagógicas. Não havia tolerância para estruturas clássicas de aula. Itens como aulas expositivas, livros textos, manuais, exigência de freqüência e de provas eram práticas mal-vistas.

O tema do exercício ainda nos colocava numa situação privilegiada para entender um conceito fenomenológico básico: a intersubjetividade ou a experiência comum que nos une e nos afirma como seres comunicantes. A intersubjetividade é definida como a comunicação das consciências individuais, umas com as outras, realizada com base na reciprocidade (Kaelin \& Schrag, 1989). Essa reciprocidade, no caso deste exercício, presentava-se ${ }^{3}$ no convívio com a escola e com as atividades de aula, e seria comum a todos aqueles que fossem capazes de ler o presente texto. Todos nós sabemos que a atividade convencional de aula implica em alguém que ensina ou que viabiliza condições para que outros aprendam e construam seu conhecimento. Também conhecemos as condições gerais das escolas públicas brasileiras. Sabemos distinguir uma escola particular para ricos e uma escola pública de periferia, e distinguimos facilmente os prédios de uma escola pública que se caracterizam quase sempre pelo abandono e mal-trato.

Nosso convívio com a atividade de aula evoca as muitas variedades desta experiência. Certamente, em nossa memória existem lembranças de aulas agradáveis e produtivas, de professores interessantes e eficientes, e de colegas amáveis e companheiros. No entanto, não pode-

\footnotetext{
3 O verbo presentar é pouco usado, no entanto é o melhor modo de enfatizar a condição fenomenológica de um mundo que se mostra antes de qualquer representação.
} 
mos negar que freqüentamos aulas monótonas e improdutivas, que tivemos professores relapsos e ineficientes, e colegas antipáticos. A combinação destes contrastes é também uma experiência conhecida: Professores monótonos, mas eficientes; aulas cansativas, mas importantes; professores simpáticos e comunicativos, mas que pouco acrescentou à turma. Estivemos na aula em diferentes estados de disposição física. Algumas vezes desfrutamos o melhor do nosso alerta mental, noutras estávamos cansados, adoentados, ou simplesmente com o pensamento bem longe dali. De qualquer maneira, o cotidiano da experiência em aula é como os demais cotidianos de nossas vidas: uma variação de diferentes emoções, estados de ânimo e disposição física. O conhecimento da situação de aula é simultaneamente uma experiência comum e singular. É comum porque todos a conhecemos, enquanto vivência básica na nossa formação. É singular porque cada um de nós tem a sua própria história com relação à escola, a professores, a colegas e a diferentes disciplinas. Desta forma, a experiência de aula se constitui em parâmetro que funciona como referência em todas às vezes que abordamos esse tema.

\section{Critério de Análise}

O material recolhido foi analisado em três etapas, cada etapa seguindo as três reflexões fenomenológicas (descrição, redução e interpretação), distinguindo em cada uma, os procedimentos técnicos dos lógicos.

Na Primeira Etapa (descrição) procedi a leitura e a ordenação dos depoimentos de 1 a 9 (Anexo A), tendo como critério a abrangência e a perspectiva apresentada pelo participante. Assim, recebeu o número 1 aquele depoimento definiu a boa aula, listando seus fatores constituintes e consensuais. Os depoimentos 2, 3, 5, 6, 7, e 8 foram variações e ampliações dos constituintes da boa aula já identificados na resposta 1 . A resposta 4 foi também uma variação das respostas mencionadas. No entanto, o participante enfatizou a experiência pessoal dele, isto é, como se sentia quando numa boa aula. Por fim, o depoimento 9 foi uma visão futurista de uma aula. Notese nesta descrição fenomenológica técnica a emergência da lógica do pesquisador na ordenação das respostas que não deixa de ser uma redução simplificada e uma interpretação intermediária.

Na segunda etapa (redução) revi cada depoimento para demarcar as unidades de sentido, isto é, identificar e nomear percepções, experiências, opiniões, conhecimentos e sentimentos expressos no texto. Um exemplo desse procedimento técnico está na Tabela 1. As unidades foram definidas por termos nativos extraídos das próprias palavras do participante. A demarcação das unidades de sentido seguiu um modelo conservador de reescrita. No entanto, tal procedimento não é realmente necessário. Ele pode ser simplificado em indicações de frases chaves elucidativas diretamente no texto recolhido, denominadas de termos nativos. Em seguida os termos nativos foram reduzidos para termos analíticos que foi a aglutinação das unidades por convergência temática. A transformação de termos nativos em analíticos permitiu a proposição de cinco grandes temas: 1) condições gerais da aula, que incluiu ambiente físico, relacionamento interpessoal entre professor e alunos, papel do professor, fatores psicológicos como motivação de alunos e professor, relação da aula com o curso do aluno, tamanho da turma e infra-estrutura; 2) papel do estudante, que inclui aspectos como a liberdade de opção do aluno para estar em aula, interesse pela disciplina, requisitos a serem atendidos a fim de estar preparado para a aula, por exemplo, conhecimento prévio, maturidade pessoal, condições físicas, e treino para participar da aula; 3) papel do professor, que é a preparação prática e teórica nas especificidades da disciplina, e o questionamento sobre ter ou não ter professor; 4) dinâmica da boa aula, que incluiu os aspectos operacionais, por exemplo, modo de iniciar a aula, escolha de assunto, participação dos alunos, modos de intervenção do professor e de finalização das atividades do dia; e 5) informações complementares, que elucidavam determinados aspectos das perspectivas apresentadas nas respostas.

Na terceira etapa (interpretação) preparei a síntese descritiva que será a concretude intersubjetiva da pesquisa. Os procedimentos técnicos e lógicos das duas etapas anteriores foram apenas indicados e exemplificados. Exercem o mesmo papel de dados brutos da pesquisa quantitativa que, enquanto tais são ausências representadas por parâmetros estatísticos e interpretadas com base em tabelas e resultados numéricos. A tríade lógica também está presente na análise quantitativa, certamente como domínio de procedimento técnico e de lógica interpretativa. A clara descrição dos procedimentos técnicos favorece a replicação do estudo para comparação dos achados. A replicação da pesquisa fenomenológica apresenta-se como uma tarefa concomitante à leitura, tendo como ponto de partida a síntese descritiva. Essa síntese estabelece a interação intersubjetiva entre o pesquisador e o leitor, para acompanhamento e crítica da análise proposta. Ao mesmo tempo, a descrição é o fim de um ciclo, no qual exerce simultaneamente a função de interpretação, e o início de um novo ciclo de análise. Desta forma, a exposição dos resultados seguirá a seqüência seguinte: 1) descrição, que trará o entendimento do que é uma boa aula na intencionalidade dos participantes; 2) redução, que apontará os elementos essenciais da descrição, utilizando para tanto o exercício das variações imaginárias (como poderia ser com a presença disto e a ausência daquilo e assim sucessivamente); e 3) interpretação, que fará o confronto das intencionalidades, sendo o pesquisador livre para imaginar, criticar e propor, usufruindo da mesma liberdade das interpretações especulativas dos pesquisadores quantitativos. Essa última parte da pesquisa é eminentemente lógica. 


\section{Descrição Fenomenológica}

Uma boa aula é um processo de envolvimento produtivo entre um grupo de pessoas interessadas num determinado tema que é denominado turma, e uma outra pessoa que coordena os trabalhos e que é denominado de orientador, professor ou coordenador. A boa aula promove a exploração e aprofundamento do tema escolhido através da troca de experiências e de conhecimentos entre os membros da turma, que são denominados de alunos. Enquanto processo produtivo, a aula facilita a melhor compreensão do tema, suscita debates despertando novas dúvidas. Esse processo de troca de vivências e informações é denominado de crescimento. $\mathrm{O}$ conceito de crescimento é amplo, pois indica o desenvolvimento dos alunos em todos os sentidos.

Tabela 1: Exemplo de definição temática e identificação de termos nativos

\begin{tabular}{|c|c|}
\hline TEMATIZAÇÃO & TRANSFORMAÇÃO \\
\hline $\begin{array}{l}1.1 \text { É difícil caracterizar o que } \\
\text { vem ser uma boa aula, pois, } \\
\text { para mim, isto significa defi- } \\
\text { nir e limitar todo um processo } \\
\text { de interação de "n" variáveis } \\
\text { que se combinam e determi- } \\
\text { nam uma boa aula. }\end{array}$ & $\begin{array}{l}\text { 1.1 Boa Aula/defnição: } \\
\text { - Caracterização difícil, pois } \\
\text { requer definição e limitação } \\
\text { de um processo de interação e } \\
\text { combinação de "n" variáveis. } \\
\text { (1.1). }\end{array}$ \\
\hline $\begin{array}{l}\text { 1.2 Entre estas variáveis estão } \\
\text { a turma, o professor, o assunto, } \\
\text { a maneira como é discutido, o } \\
\text { manejo do professor. (Se é um } \\
\text { professor autoritário, democrá- } \\
\text { tico, pseudo-democrático), o } \\
\text { interesse pelo assunto, a serie- } \\
\text { dade necessária, para se tratar } \\
\text { o assunto, a visão prática da- } \\
\text { quilo que se está aprendendo, o } \\
\text { levantamento de necessidades } \\
\text { de se ir mais além daquilo que } \\
\text { se discute na aula, a interação } \\
\text { professor aluno, o momento } \\
\text { espaço-temporal da aula, o âni- } \\
\text { mo das pessoas presentes, etc. }\end{array}$ & $\begin{array}{l}\text { 1.2 Boa Aula/lista possível de } \\
\text { variáveis: } \\
\text { - turma; } \\
\text { - professor; } \\
\text { - assunto (tema); } \\
\text { - a maneira como o tema é dis- } \\
\text { cutido; } \\
\text { - interesse pelo assunto; } \\
\text { - seriedade necessária; } \\
\text { - visão prática do que está sen- } \\
\text { do aprendido; } \\
\text { - levantamento de necessidade } \\
\text { de ir além; } \\
\text { - interação professor aluno; } \\
\text { - ânimo das pessoas presentes } \\
\text { (1.2). }\end{array}$ \\
\hline $\begin{array}{l}\text { 1.3 Dadas inúmeras variáveis } \\
\text { que podem contribuir para } \\
\text { este processo não creio que se } \\
\text { possa definir uma boa aula. }\end{array}$ & $\begin{array}{l}\text { 1.3 Boa Aula/definição: } \\
\text { - constatação de que inúmeras } \\
\text { variáveis contribuem para o } \\
\text { processo (boa aula) impedem } \\
\text { a proposição de uma definição. } \\
\text { (1.3). }\end{array}$ \\
\hline $\begin{array}{l}\text { 1.4 E sim que quando existe } \\
\text { uma inter-relação harmôni- } \\
\text { ca de todas as variáveis e um } \\
\text { progresso com crescimento de } \\
\text { todos os participantes da aula- } \\
\text { processo, crescimento em to- } \\
\text { dos os sentidos, aí sim, podere- } \\
\text { mos dizer, com mais precisão, } \\
\text { que isso caracteriza o que vem } \\
\text { a ser uma "boa aula". }\end{array}$ & $\begin{array}{l}\text { 1.4 Boa Aula/definição: } \\
\text { - é um processo que "aconte- } \\
\text { ce"; } \\
\text { - quando existe uma inter-rela- } \\
\text { ção harmônica de as variáveis; } \\
\text { - quando ocorre um cresci- } \\
\text { mento de todos os participan- } \\
\text { tes; } \\
\text { - quando este crescimento é } \\
\text { em todos os sentidos (1.4). }\end{array}$ \\
\hline
\end{tabular}

Depoimento do Participante 1
A boa aula acontece em ambiente físico confortável, limpo, com cadeiras macias, com boas condições de luminosidade e silêncio, onde os participantes possam ouvir uns aos outros. A aula pode ser tanto em uma sala quanto ao ar livre. Seja qual for o local, ela estará sempre próxima a uma biblioteca com acervo adequado.

A turma é pequena e se posiciona em círculo para facilitar a troca de conhecimentos e de opinião crítica. Os alunos estão nesta turma por opção. O tema é de interesse e reconhecido como pertinente para a formação na profissão e especialidade escolhida. Há também nesses alunos uma clareza quanto aos motivos que embasaram a escolhas das disciplinas. Observa-se neles maturidade pessoal e disposição mental e física para o trabalho. Todos eles apresentam boas condições de tempo e de material para o estudo.

Uma boa aula é preparada com antecedência. Primeiro escolhe-se o tema específico do dia. Esta escolha é consensual entre os participantes (professor e alunos). A seguir, escolhe-se o material que será previamente lido por todos. A leitura produz reflexões e inquietações e prepara a participação dos alunos para as exposições e debates.

O professor, se houver, é um profissional competente e experiente, com conhecimento amplo e profundo em seus aspectos teóricos e práticos. Por estar familiarizado com o tema, ele trará elaborações pessoais, não se restringindo as sínteses ou sistematizações de leituras. O professor é um apaixonado pelo tema e está empenhado em apresentá-lo aos alunos. Cabe ao professor: coordenar as atividades, esclarecer ou suscitar dúvidas, articular as contribuições dos alunos, trazer subsídios e contribuições diferenciadas, e apresentar uma síntese do material discutido de modo a melhor organizá-lo e integrá-lo.

O professor pode intervir nas atividades por iniciativa própria ou por solicitação de algum aluno. Contudo, o professor não é uma condição necessária à boa aula. Os alunos poderão escolher entre eles um colega com maior conhecimento e experiência para exercer essa função. Outro modo é modificar o conceito de turma para incluir alunos em diferentes níveis de conhecimento. Nesse caso, os mais adiantados chamam a atenção dos mais novos para aspectos que eles não estão percebendo. Em contrapartida, os mais novos instigam aos mais adiantados a revisarem criticamente seus conhecimentos mais fundamentais.

A boa aula inicia de várias maneiras. Pode iniciar com proposta clara do professor ou de algum aluno quanto à exploração e discussão do tema especificado, ou mesmo com uma discussão livre sobre o tema em que os participantes trazem diversos aspectos do material lido e refletido. Outro modo de iniciar é solicitar aos alunos que já possuam conhecimento do tema a introduzi-lo criticamente. De qualquer modo, é a turma enquanto grupo que tem a palavra final sobre o melhor modo de conduzir o trabalho.

Uma boa aula não é restrita a exposições do professor, dos alunos ou da participação de todo o grupo em forma de seminário (uma situação de aula em que em cada ses- 
são um ou mais participantes se encarregam da apresentação de um determinado aspecto do tema geral). Outras atividades que também ocorrem são as exemplificações de como levar o tema em estudo para a prática, a comparação de outras perspectivas ou abordagens sobre o tema em discussão e, ainda, a apresentação de palestras por profissionais especializados.

Em uma boa aula, vez por outra, acontece um episódio engraçado o que diverte e evita a monotonia. Nessa boa aula a referência de tempo passa a ser as indicações físicas de cansaço ou solicitações de outros compromissos assumidos. O aluno sente-se parte integrante da construção e constituição de algo que se configura e se transforma com suas próprias mãos. A aula termina com as indicações dos alunos de que já alcançaram seus limites de conhecimento para aquele dia. Por fim, encaminha-se a aula seguinte, se for o caso. Essa boa aula conta com excelente infra-estrutura. Taquígrafos e datilógrafos transcrevem os debates e preparam as sinopses que servem de consulta e de sistematização para os estudos dos alunos e do professor. As aulas são também gravadas em videoteipe e podem ser revistas por todos os alunos antes da aula seguinte, espontaneamente. Esses teipes e sinopses também estão acessíveis aos alunos que faltaram. Nenhum aluno comparece a aula sem está informado do que ocorreu na aula anterior. O relacionamento interpessoal entre alunos, e entre alunos e professor é da melhor qualidade. Todos se tratam com cordialidade e respeito mútuo e sabem conviver com suas diferenças.

\section{Esclarecimentos Lógicos da Descrição}

A descrição é para Husserl (1913/1975) o retorno à experiência imediata da consciência, ocorrendo neste momento a epoché ou suspensão das pressuposições daquele que descreve. O que está sendo descrito não é a situação real do conjunto de respostas, mas a consciência essencial e delimitadora do conjunto de respostas de quem descreve. Para Merleau-Ponty (1945/1994; 1964) a descrição reconhece que o fato existe (a aula), antes de qualquer análise que eu possa fazer sobre ele (fundamento etnográfico). Enquanto fenômeno, eu tomo a aparência da boa aula na forma em que foi expressa, sendo a minha descrição a transição entre o discurso dos outros e o meu discurso (semiótica). Nesta descrição, aquele que descreve desaparece abrindo espaço para o aparecimento do fenômeno, não havendo nesta transição nem experiência interna e nem externa (fenomenologia).

\section{Redução Fenomenológica}

A redução fenomenológica inicia-se estabelecendo uma distinção entre aula e boa aula. O enunciado "como seria uma boa aula” foi respondido em termos das con- dições necessárias para que uma aula fosse idealmente produtiva. A pergunta em si já foi um convite para uma exploração imaginativa. As respostas reconheceram que uma aula ocorre em uma determinada estrutura, combinando diversos elementos que foram especificados. Neste sentido, há uma variação de ênfase entre os depoimentos: eles podem concentrar-se na informação otimizada dos elementos da boa aula, podem destacar um par de elementos que por contraste ou combinação podem ser importantes na realização da boa aula; ou podem reconhecer a estrutura tradicional de aula para depois modificá-la e defini-la em termos possíveis, mas nem sempre convencionais.

Qual seria a distância da aula real para a aula ideal que estes alunos imaginaram em suas descrições? Um primeiro passo para responder a pergunta é localizar o contexto referencial dos alunos, ou seja, qual curso, qual universidade e qual época. Para tanto vou recorrer a um diálogo imaginário com o mundo vivido pelos participantes, procurando trazer a infra-estrutura de vivência e imaginar uma possível justificação.

O contexto é um curso de psicologia de uma universidade pública brasileira em 1986. O ambiente geral de aula em que eles convivem é em um prédio de algumas décadas de uso, não muito bonito. Há certo esforço de limpeza, mas o piso parece não recebê-la bem, pois nunca me aparece muito limpo. Há arquitetura original do prédio é violada constantemente para atender demandas das mais diversas, sendo os espaços reservados para convívio transformados em salas de professores ou laboratórios, copiadoras, etc. As paredes podem conter pichações, as salas nem sempre contam com ambientação climática e tratamento acústico. $\mathrm{O}$ campus não havia descoberto ainda o conceito de convívio e de bem-estar universitário. As aulas competiam com todo o barulho que vinha das ruas de uma grande cidade. As cadeiras não eram anatômicas e podiam até estar quebradas, quando não com um prego meio solto que poderia rasgar a roupa. A biblioteca dispunha de poucos livros e de espaços limitados para leitura. Os alunos eram selecionados em concurso vestibular muito concorrido, havendo grande chance de que as vagas fossem ocupadas pelos mais bem preparados e oriundos de escolas particulares bem equipadas. Por outro lado, o curso caracterizava pela tradição profissionalizante com pouca atenção à pesquisa. Uma tradição consistente com as condições históricas da organização dos cursos de psicologia no Brasil. Esses cursos, em seus primórdios, contaram com a colaboração professores transferidos de outras disciplinas, sem maiores vínculos com a psicologia que se desenvolvia na Europa e nos Estados Unidos, embora muito deles tenha sido grandes empreendedores na implantação de diversas práticas, principalmente no campo da avaliação psicológica.

Esses alunos viviam numa época em que o país saia de um regime ditatorial e estava ansioso por práticas participativas. Qualquer função que representasse autoridade 
era mal-vista e devia ser afastada. Esses alunos questionavam a presença, mas não a função do professor, certamente entendido como facilitador. Desta forma, é compreensiva a posição de que poderia haver um professor, mas se houvesse deveria preencher determinados pré-requisitos, exatamente a falta histórica referida acima, mas até certo ponto, Nem sempre pesquisadores reconhecidos são bons professores nos termos tradicionais, mas podem passar com êxito uma perspectiva instrumental, crítica e produtiva do conhecimento.

A dinâmica da aula e também seu conteúdo é centralizado no debate, na crítica e na participação. Os informantes parecem acreditar que o conhecimento é produto progressivo do debate. $\mathrm{O}$ debate contém algumas regras: os participantes não deverão se alongar nas intervenções e devem estar atentos as colocações e contribuições dos colegas. O debate é uma atividade tão importante nesta boa aula que participantes devem se apresentar preparados na arte da argumentação. As dificuldades interpessoais inerentes ao convívio humano foram reconhecidas na figura de autoridade do professor que pode polarizar a relação, e na intolerância e no abuso da crítica entre colegas que pode trazer inimizades e inibições. A crítica é bem vinda, mas não pode ser precipitada, requer atenção, reflexão e mesmo leituras.

Os informantes reconhecem que uma boa aula depende de alunos bem preparados. Mas como criar condições para esta preparação? Tais condições não poderão ser exigências do professor, nem do regulamento do curso. O impasse é resolvido no paradoxo de que sempre os alunos cuidariam de preparação prévia sem exceção, mas voluntariamente. Há aqui o reconhecimento de uma exigência, mas desde que seja atendida pela autoconsciência e autocrítica do aluno, uma expressão legítima de sua opção, interesse e desejo de estar naquela atividade. Não deixa de ser interessante esta definição internalizada do lócus de controle.

A ênfase no debate e na crítica traz outro aspecto importante. Revela que a natureza do conhecimento que estes alunos estão habituados não é de ordem taxonômica ou técnica, mas interpretativa e consensual. Parece muito mais o desenvolvimento de uma habilidade argumentativa e de um exercício de crítica intelectual, talvez vivencial, do que um conhecimento cientificamente embasado para sustentar uma prática profissional e ética.

Para estes alunos uma aula deve sempre ser um momento de excepcional grandeza intelectual da qual se extrai insights arrebatadores, jamais imaginados. Essa crença deve-se, certamente, a uma contextualização histórica do ensino universitário brasileiro. Existiu até a década de sessenta uma tradição de professores bem falantes e com conhecimentos enciclopédicos. Estes professores, com suas exposições abrangentes e empolgantes compensavam a falta de livros e revistas nas bibliotecas. Eles eram estudiosos de grande curiosidade, proprietários de boas bibliotecas, bem informados, mas sem preparo em pesqui- sa empírica e em produção de conhecimento. Animavam as aulas, davam boas orientações profissionais, entusiasmavam o estudante para o estudo, mas eram repetidores. Não foram, com raras exceções, exemplos de cientistas. Legaram, contudo, o mito da aula magna, aquela que surpreende e ultrapassa.

Estes estudantes representam uma geração que chegaram ao curso universitário em meio a um vazio docente. Os professores da antiga tradição haviam desaparecido pela reforma universitária de 1970. Professores realmente competentes foram afastados da Universidade pela ditadura militar. No vazio docente da década de setenta, recrutou-se professores para a universidade de muitas maneiras. No entanto, foram raras as contratações pela via do concurso público que elegia como critério a titulação acadêmica, acompanhada da evidência de produção científica e do desempenho didático.

Esta situação agravou-se, sobremaneira, na área da psicologia pela influência difusa e muito persistente da didática humanista. Elas foram decorrentes de transposições clínicas para a escola, sem amparo sistemático na evidência empírica. Também não avaliava os resultados produzidos, quando o fez, a decepção foi grande. Para essa cultura pedagógica, levar o programa da disciplina no início do semestre era um desrespeito ao aluno. Ele deveria ser ouvido antes de qualquer decisão sobre o programa.

No lugar das aulas expositivas dos catedráticos vieram os seminários e as técnicas de grupo. Dessa última, a mais popular era a divisão da turma em vários grupos, reunidos na mesma sala para a leitura de um determinado texto. O professor percorria os grupos para um ou outro esclarecimento e, quem sabe, oferecer uma pergunta para reflexão.

A falta de tradição acadêmica na área da psicologia fez com que estes alunos não convivessem com professores preparados para trabalhar com as disciplinas básicas e introdutórias do curso. Como o currículo tinha que ser obedecido, pode-se imaginar o deslocamento de professores, contra vontade, de disciplinas profissionalizantes, criando a situação do não-conhecimento e da não-paixão.

$\mathrm{Na}$ época havia restrições tanto ao livro texto, quanto aos modelos de procedimentos e técnicas. Esses recursos eram mal-vistos pelos riscos que ofereciam, limitando a exploração diversificada e criativa do aluno. Os alunos deveriam sentir-se livres para explorar o conhecimento nas suas mais variadas fontes.

Há no depoimento dos participantes um forte conteúdo hedonista. A variação imaginária para a descoberta do invariante deste sentido trouxe ambigüidades. De um lado, uma atividade terá êxito se também se constitui em prazer. Por outro, estamos diante de uma geração hedonista por conta de mudanças importantes na estrutura familiar, nas relações entre pais e filhos, e no reinado da vontade dos filhos em vigência na época. Também se sabe que a realização bem sucedida de uma tarefa requer, além da inspiração, muito esforço e transpiração. 


\section{Esclarecimentos Lógicos da Redução}

A redução apresentada alinha-se com a proposição de Husserl, recorrendo à imaginação livre para estabelecer um diálogo crítico com a síntese descritiva. A epoché ocorreu na primeira reflexão e agora o ato da consciência começa a se diferenciar do seu objeto, com a expansão do eu do pesquisador e o encolhimento do eu do outro. Aos poucos a intenção do pesquisador vai se tornando presente e os seus viéses surgem na realização da Gestalt radical da experiência descrita. No entanto, na diferenciação entre o eu e o outro, o ato intencional conduz a construção de um novo objeto que será a interpretação. Para Husserl será a descoberta da intencionalidade, e para Merleau-Ponty o significado da experiência, aqui presente nas demandas dos participantes e nas delimitações do mundo.

\section{Interpretação Fenomenológica}

Aprendemos com a descrição que uma boa aula é um processo de troca de conhecimentos e experiências, em condições ótimas de ambiente físico, de convívio interpessoal, de preparo intelectual e de boa disposição dos participantes. A dinâmica de trabalho é centrada no debate, em clima de liberdade e de respeito mútuo. A redução ajudou-nos a comparar a imaginação idealizada enquanto movimento desejante e a vivência da aula real, enquanto definição de ausências pela intensificação das ênfases. A comparação foi possível através da identificação e exame contextual da aula real destes estudantes e do mundo histórico da época. A comparação trouxe a Gestalt radical da experiência.

O que emerge para a interpretação é um movimento entre uma aula real precária, na qual vários valores são transgredidos, e uma aula ideal, na qual tais valores são resgatados e experimentados imaginativamente em toda plenitude. Estes informantes, ao descreverem a aula ideal denunciam a aula real, precária, que não deveria existir. Ao apontar para a aula ideal, eles demolem a aula tradicional conhecida, mas preservam a aula clássica universitária, esta sim a grande ausente dos depoimentos e do contexto desses participantes.

A preservação da aula clássica universitária está no reconhecimento da diferenciação operacional de papéis e na estratificação de conhecimentos e experiências dos participantes. Para a boa aula, tem que haver papéis funcionais de planejamento e coordenação, e níveis de conhecimento diferenciados. Quanto à dinâmica, apesar da preferência pelo debate, não se descarta a exposição, deste que seja apresentada com competência.

O questionamento da figura do professor não desconsidera a necessidade do papel funcional de coordenação. Questiona-se, sim, aquele participante que embora investido de autoridade funcional, apresenta-se destituído de autoridade referencial. O que esses estudantes desejavam encontrar na boa aula era professor com leitura e articulação própria, conhecedor e inovador da prática, e capaz de globalizar e sistematizar o conhecimento. Nesta síntese os estudantes identificam tanto o pesquisador professor que está envolvido em linha de pesquisa bem definida, em produção continuada de conhecimento; quanto o professor pesquisador que é capaz e com competência de extrapolar os limites de sua pesquisa para oferecer uma visão mais geral e sistematizada da sua área. Claro que eles não trouxeram essa observação, até porque a desconheciam. Mas essa condição resolveria a produção de material didático que para eles seriam as transcrições dos debates.

A ausência deste professor, com formação própria e criatividade produtiva, desequilibra os constituintes da aula. Curiosamente, esta falta é reconhecida, no entanto é dada como aspiração impossível. Veja-se, que no esforço de remediar, estes estudantes recorrem aos grandes valores da época: igualdade, liberdade e participação. As duas primeiras reflexões mostraram que os participantes da pesquisa foram bem sucedidos ao definirem os problemas. No entanto, a interpretação agora mostra que ao apontar soluções eles não ousaram romper fronteiras tradicionais. Por exemplo, no caso da infra-estrutura eles se limitaram a apontar para inovações tecnológicas que embora existentes, ainda eram faltas notórias na universidade da época.

Quanto ao comportamento dos estudantes, há o reconhecimento da estrutura de aula clássica. Pois se requer deles: envolvimento efetivo nas disciplinas no estudo e na participação. No entanto, tal exigência deve ser alguma coisa internalizada e autoconsciente, não externa e imposta. Tal condição poderia ser alcançada com preparação especializada, construída na própria seqüência e progressão curricular.

A primeira reflexão mostrou que a boa aula provocaria um envolvimento tão profundo que haveria dificuldades de estipulação de horários ou outros aspectos operacionais necessários à organização das atividades universitárias. Nessa lógica, a boa aula seria um empreendimento inviável. Contudo, esta força de expressão é um deslocamento de ênfase para anunciar o comprometimento com uma obra em construção a qual se deseja avançar apaixonadamente. $\mathrm{O}$ que ocorre aqui é a não diferenciação de espaços, certamente pela confusão universitária que a segunda reflexão nos apontou. A aula não é parte de um processo maior. É, para os participantes, um fato em si com uma intensidade e energia própria que cessaria, apenas, na exaustão. Essa dificuldade de estabelecer limites de espaço e tempo é uma verdade para a realização de qualquer tarefa criativa. Por exemplo, a pesquisa é uma tarefa criativa, intensa, com dificuldades de se estabelecer entre limites habituais, seja em procedimentos de laboratório, seja na preparação de textos e conferências. Esses estudantes desconheciam esse outro lado universitário, mas sentiam a falta de alguma coisa nessa direção.

A interpretação mostra, enfim, que ao isolarmos os variantes temporais (os valores de uma época) e ao defi- 
nirmos os invariantes constitucionais (os elementos da atividade em si), chegamos a uma definição de boa aula, que é na verdade uma aula universitária clássica. Se o contexto da boa aula é um país no qual a educação é um valor fundamental, resolve-se o problema do ambiente físico, da biblioteca e da infra-estrutura. Então, competência, seriedade e comprometimento passam a ser condições necessárias, enquanto interesse, compartilhamento e paixão tornam-se condições suficientes para que realmente exista uma aula que pode até ser boa. No entanto, os depoimentos trazem um clamor por uma reforma universitária capaz de dar forma e sentido as suas ações: revisão de práticas arcaicas e burocráticas e implantação de práticas flexíveis e pró-ativas, voltada ao incremento da aprendizagem autônoma e continuada.

\section{Esclarecimentos Lógicos da Interpretação}

A terceira reflexão foi definida por Husserl (1913/1975) de redução transcendental. O interesse não mais está voltado à experiência primordial, aquela do objeto da percepção (primeira reflexão), mas concentrada na lógica do eu que por seu afeto, cognição e conação atribui intenção aos objetos e aos atos da consciência. A crítica metodológica à terceira reflexão é quanto ao risco de subjetivismo: as falhas na captação de uma rede intersubjetiva. Em contraposição, as contribuições serão a abstração e a generalização do fenômeno. Tem-se então uma propriedade correspondente ao conceito em uma ciência básica. Merleau-Ponty (1945/1994) recolocou a terceira reflexão a serviço das ciências sociais, como especificação de um sentido que está posto ao mundo, como uma nova consciência impelindo-me ao movimento, à ação e à mudança. Curiosamente, esse exercício fenomenológico sobre a boa aula presta-se as duas proposições fenomenológicas, pois define os elementos constitutivos da aula (modo de ser), mas vocaliza questões referentes ao desempenho e aproveitamento da aula (modo de relação).

\section{Considerações Finais}

As considerações finais retomam o problema da distinção entre procedimentos técnicos e lógicos em quatro aspectos: 1) reconhecimento da pouca explicitação da lógica triádica nas pesquisas fenomenológicas; 2) complexidades expositivas da lógica triádica; 3) relevância do método fenomenológico; e 4) relações entre método e ciência.

Entre os anos de 2000 e $2006^{4}$, foram publicados 53 artigos no Journal of Phenomenological Psychology, 18 dos quais eram relatos de pesquisa empírica. Nesses artigos, a tríade lógica não era uma constante, tampouco a explicitação de procedimentos fenomenológicos básicos como a epoché. Com efeito, não se pode esperar algum tipo de ênfase entre procedimentos técnicos e lógicos, como prática corrente. É trabalhoso, complexo e dispendioso. No entanto, espera-se que a explanação de métodos e materiais não se contente com a exposição de procedimentos técnicos e organizadores da análise, negligenciando a lógica da intencionalidade situada e a lógica da intencionalidade apropriável, aquela que emana dos objetos. Tal procedimento ressalta o objeto, mas omite o ato da consciência. Lanigan (1997) ilustra com clareza a lógica triádica ao distinguir: tipos de evidências, estrutura de análise, e regras de julgamento para validade. Os materiais analisados por Lanigan foram relatos recolhidos por A. R. Luria (1974/1994) sobre desenvolvimento cognitivo em populações camponesas. No entanto, o artigo de Lanigan é mais uma exceção do que uma regra.

Técnicas e procedimentos são orientados por uma noção econômica de ganhos e perdas. A explicitação técnica é esperada como sustentação da relação entre instrumentos e análise de dados. A explicitação lógica fica implícita na indicação de que o método é fenomenológico. Desta forma, a apresentação da análise em três passos fica apenas subtendida ou restrita a exposição teórica do método, distanciada dos estudos empíricos.

Tais considerações levam-nos à inevitável discussão da relação entre ontologia (o que é que estou estudando) e epistemologia (como estou estudando). De fato, ontologias fortes dispensam epistemologias sofisticadas. Pesquisas qualitativas bem sucedidas estão associadas a ontologias fortes, aquelas cujos dados falam por si, sem necessidade de maiores análises ou demonstrações. Exemplos desse tipo procedem das áreas da administração e marketing (Milliken, 2001) que pelas implicações econômicas dispensam maiores comentários. Tal assertiva é uma boa justificativa para o uso dos métodos qualitativos. Perguntase, então, qual é a contribuição diferenciadora da fenomenologia? DeSouza, Gomes e McCarthy (2005) sugerem que é a atitude ética do pesquisador frente ao problema que estuda e ao modo como divulga as conclusões. Ética que se viabiliza na assimilação lógica das três reflexões, seja ela em um, dois, ou três atos. A asserção contempla a diversidade de métodos e os vários entendimentos de fenomenologia. Contudo, a epistemologia não pode ganhar proeminência em relação à ontologia. A função fenomenológica é explicitar a epistemologia manifesta nos atos da consciência e é esta explicitação que transforma lógica em ética.

Métodos e procedimentos estão a serviço da ciência. Dito simplesmente, o que caracteriza a ciência é a busca do conhecimento, com o propósito de esclarecer e de indicar intervenções que desvelem os mistérios do mundo e de todos os seres que o constituem. Os fins são básicos: promoção da qualidade de vida e da preservação das con- 
dições que viabilizam a vida de novas gerações. A ciência debruça-se sobre os desafios que o conhecimento e o mundo nos trazem continuadamente, em todos os domínios ontológicos (físico, biológico, psicológico, social, cultural e interativo). Nestas circunstancias, métodos são meios e possibilidades que passam a nos interessar, enquanto arcabouço filosófico, historicidade, ou encaminhamento que leve às respostas procuradas. Métodos são acréscimos que aprimoram a nossa maneira de ver, sentir e pensar o mundo e as suas intrincadas relações. Eles são amplificações de intencionalidades (Ihde, 1979). Contudo, o modo de explicitação do ver, do sentir e do pensar daquele que pesquisa deve se afastar dos riscos da ética retórica. Neste tipo de retórica, a construção do argumento conforma-se ao que o pesquisador quer defender ou provar. A explicitação está para uma retórica ética, na qual a construção do argumento faz justiça ao situacionamento do que se quer compreender. A fenomenologia é um recurso poderoso e disponível a essa explicitação.

\section{Referências Bibliográficas}

Aristóteles (2005). Analíticos anteriores (E. Bini, tradução do grego, textos adicionais e notas) Órganon (pp. 111-250). Bauru: Edipro.

Colaizzi, p. F. (1978). Psychological Research as the Phenomenologist Views It. In: R.S. Valle \& M. King, (Orgs.) Existential Phenomenological Alternatives for Psychology (pp. 48-71). New York: Oxford University Press.

Creswell, J.W. (2007). Qualitative inquiry and research design: Choosing among five approaches. Thousand Oaks, CA: Sage.

DeSouza, M., Gomes, W.B. \& McCarthy, S. (2005). Reversible relationship between quantitative and qualitative data in self-consciousness research: A normative semiotic model for the phenomenological dialogue between data and capta, Quality and Quantity, 39, 199-215.

Dezin, N.K., \& Lincoln, Y.S. (Eds.) (2000). Handbook of qualitative research. Thousand Oaks, UK: Sage

Giorgi A. (1985). Sketch of a psychological phenomenological method. In: A. Giorgi (Org.). Phenomenological and psychological research (pp. 8 -22). Pittsburgh, PA: Duquesne University Press.

Giorgi, A. (2006). Difficulties encountered in the application of the phenomenological method in the social sciences. Análise Psicológica, 3(XXIV), 353-361.

Husserl, E. (1975) Ideas: General Introduction to Pure Phenomenology (W.R. Boyce Gibson, Trans) New York: Collier Books. (Original publicado em alemão, 1913).

Husserl, E. (1977). Cartesian meditations: An introduction to phenomenology (D. Cairns, Trans.) New York: Springer. (Originais e acréscimos publicados em alemão, 1927, 1933).
Ihde, D. (1979). Experimental phenomenology: An introduction. New York: Paragon Books.

Kaelin, E.F., \& Schrag, C.O. (Eds.) (1989). American phenomenology: Origins and developments. Analecta Husserliana, v. 26, Boston: Kluwer.

Kant, I. (1977) Prologomena to Any Future Metaphysics (L. W. Beck, Trans) Indianapolis: Bobbs-Merrill. (Original publicado em alemão, 1873).

Lanigan, R. (1992). The human science of communicology. Pittsburgh, PA: Duquesne University Press.

Lanigan, R. (1997). Capta versus Data: Métodos e evidência em comunicologia C. H. Kristensen, Trad.). Psicologia: Reflexão e Crítica, 10(1), 17-45. (Original publicado em inglês, 1994).

Mahoney, M. (1993). Desenvolvimentos recentes e futuras possibilidades em psicologia. Psicologia: Reflexão e Crítica, $\underline{6}(1 / 2), 3-16$.

Merleau-Ponty, M. (1994). Fenomenologia da percepção (C. A. R. Moura, Trad.). São Paulo: Martins Fontes. (Original publicado em 1945).

Milliken, J. (2001). Qualitative research and marking management. Management Decision, 39(1), 71-78.

Moreira, D.A. (2002). O método fenomenológico na pesquisa. São Paulo: Pioneira.

Nicolaci-da-Costa A.M. (2007). O campo da pesquisa qualitativa e o método de explicação do discurso subjacente (MEDS). Psicologia: Reflexão e Crítica, 20, 65-73.

Patton, M Q. (1990). Qualitative evaluation methods. Beverly Hills, CA: Sage.

Sanders, p. (1982). Phenomenology: A new way of viewing organizational research. The Academy of Management Review, 7, 353-360.

Shank, G. (1995). Semiotics and Qualitative Research in Education: The Third Crossroad The Qualitative Report [online] v. 2, n. 3 [citado 20 Setembro 2007] Disponível na Word Wide Web: http://www.nova.edu/ssss/QR/QR2-3/ shank.html.

Stake, R.E. (2000). Case studies. In: N.K. Dezin \& Y.S. Lincoln (Eds.). Handbook of qualitative research (2nd ed., pp. 435454). Thousand Oaks, UK: Sage

Van Kaam, A. (1959). Phenomenological analysis: Exemplified by a study of the experience of "really feeling understood". Journal of Individual Psychology, 15, 66-72.

Yin, R. (1994). Case study research. Design and methods. London: Sage Publications. 


\section{Anexo A}

\section{Sujeito 1}

É difícil caracterizar o que vem ser uma boa aula, pois, para mim, isto significa definir e limitar todo um processo de interação de "n" variáveis que se combinam e determinam uma boa aula.// Entre estas variáveis estão a turma, o professor, o assunto, a maneira como é discutido, o manejo do professor (Se é um professor autoritário, democrático, pseudo-democrático), o interesse pelo assunto, a seriedade necessária para se tratar o assunto, a visão prática daquilo que se está aprendendo, o levantamento de necessidades de se ir mais além daquilo que se discute na aula, a interação professor aluno, o momento espaço-temporal da aula, o ânimo das pessoas presentes, etc. // Dadas inúmeras variáveis que podem contribuir para este processo não creio que se possa definir uma boa aula // e sim que quando existe uma inter-relação harmônica de todas as variáveis e um progresso com crescimento de todos os participantes da aula-processo, crescimento em todos os sentidos, aí sim, poderemos dizer com mais precisão que isso caracteriza o que vem a ser uma "boa aula". //

\section{Sujeito 2}

Uma boa aula inicia com a proposta clara do orientador para o objetivo a ser tratado neste dia. O grupo de alunos não é muito grande e disposto de forma que todos possam interagir e trocar conhecimentos (em círculo), a fim de que todos possam participar e opinar criticamente sobre o assunto. O lugar onde o grupo se encontra é claro e arejado para que os participantes sintamse dispostos a trabalhar. Após todos os participantes, inclusive o orientador (professor) concordarem acerca do tema, o grupo se organiza de forma a estudá-lo em conjunto. Esta organização é sob a forma de ler e discutir acerca do assunto ou simplesmente ouvir alguns dos participantes que já possuam maior conhecimento deste, discutindo-o. O estudo é um aprofundamento do tema, explorando-o através do material à disposição e enriquecendo-o com as experiências e conhecimentos de cada um sobre ele. Como o orientador do grupo possui vivência maior, ajuda os alunos a esclarecerem dúvidas ou fornecer outras que não surgiram no momento. Quando todo o grupo acredita ter alcançado seus limites de conhecimento para este dia, a aula é encerrada, tendo ela criado em todos os alunos uma curiosidade de explorar ainda mais o assunto.

\section{Sujeito 3}

Em primeiro lugar, vamos supor que as pessoas que participam daquela aula estão interessadas no assunto, desejantes de conhecer mais a respeito deste (por motivos os mais diversos) e já com algumas colocações, formu- lações (diferentes também) sobre o mesmo. O professor deveria ter um conhecimento profundo, amplo e atualizado do assunto a ser colocado. Este seria apaixonante para ele; seu conhecimento não seria apenas teórico, mas partiria também de uma prática. O professor seria principalmente um bom colocador de questões, tanto sobre o que os alunos trazem - ele daria espaço para estes participarem. Seria também um bom sistematizador para dar uma organizada sobre o que se discute em aula. Cumpridos estes pré-requisitos das pessoas que participam na aula esta se desenrolaria mais ou menos assim: Previamente combinou-se para discutir uma temática naquele encontro, as pessoas leram textos, pensaram, refletiram, criaram inquietações sobre o mesmo. Começa-se com uma, discussão livre, alguém ressalta tal ponto que o tocou e por esta ponta vai se entrando no tema através de confrontações, esclarecimentos, etc. dos participantes. Quando o professor, ou mesmo um estudante o acha conveniente e o solicita; o professor estende-se sobre um determinado aspecto, esclarece, situa, explicita, relaciona. Também pode retornar o mais relevante na discussão até aquele momento e dar-lhe uma organizada para então continuar. No fim da aula dá-se um encaminhamento de como dar seguimento (se é o caso) a discussão no próximo encontro. $\mathrm{O}$ aspecto relacional também é importante. Entre professor e alunos, e entre estes, o relacionamento, seria de cordialidade e respeito mútuo; e de vez em quando haveria um episódio engraçado. (OBSERVAÇÃ̃: Não quis "voar" muito coloquei apenas o que eu acho minimamente necessário para que uma aula universitária seja boa.)

\section{Sujeito 4}

Estou particularmente interessada no assunto. Não tenho sono, sinto-me alerta e excitada. Estou disposta a trabalhar e tudo que me interessa é conhecer, destrinchar, investigar, sugar. Apropriar-me do conhecimento até o ponto de poder ultrapassá-lo. Pode haver um professor. Há um professor. Ele entende do assunto e eu o escolhi. Ele é apaixonado por isso e está empenhado em transmitir o que sabe, em construir novos degraus, em investir no aluno, em mim, em quem queira trabalhar. Essa boa aula eu posso ser Denise e quanto mais eu for Denise, melhor será para esse conhecimento, para essa ciência que está sendo, ao mesmo tempo, devorada e construída. O tempo não passa pelo relógio e a hora de parar é a hora da fome, do cansaço ou de outro compromisso. Nessa boa aula eu tenho a exata e lúcida consciência de que eu quero estar ali, de que estou ali porque quero. É algo que constitui, acrescenta. É como colocar camadas e ir dando conformação, sustentação. Constituir. Nessa boa aula eu me sinto assim me constituindo por mim, por minhas mãos, com algo que transformei em meu. 


\section{Sujeito 5}

Para mim, seriam dois elementos básicos para se ter uma boa aula: um ambiente propício e motivação. Em primeiro lugar, o ambiente físico. Teria que ter um mínimo de conforto, onde não existissem cadeiras duras incômodas. A luminosidade, espaço e higiene seriam outros fatores que influenciariam. Ainda dentro do fator ambiente, procuraria existir um clima agradável entre as pessoas. Onde todos pudessem colocar suas opiniões e posicionamento sem uma crítica destrutiva, isto é, sem uma depreciação dos mesmos, ou seja, uma melhor aceitação entre as pessoas. Também precisaria haver uma melhor distribuição de papéis, isto é, sem a autoridade-professor e os alunos do outro lado, bem como também uma melhor e maior comunicação entre eles. Sobre motivação, seria necessário um tema interessante, tanto para os alunos como para o professor, para que houvesse uma compreensão e um debate sobre o mesmo tentando assim um maior conhecimento. Seria também incluído neste fator maneiras diferentes, talvez mais dinâmicas, de abordagem sobre os temas propostos para serem estudados. E por último, pessoas que realmente sejam profissionais em suas áreas e que sintam prazer em transmitir e levar ao conhecimento dos outros suas experiências. Aulas mais dinâmicas: não só seminários ou aulas expositivas. Uma maneira seria ler sobre o assunto e aplicá-lo ou vê-lo na prática com sua posterior crítica e relato. Ou ainda, um determinado tema visto sobre as diferentes correntes de psicologia - aqui podendo ser teórico ou/e prático. Outro, confronto, também teórico e prático, entre as diferentes linhas de psicologia podendo ser agrupadas 2 a 2 . Outra maneira, promover palestras com pessoas especializadas nas diversas correntes de psicologia e promover debates. Para começar dividimos a aula em dois pólos - ressalvando que esta não é a única maneira de se pensar uma aula e supondo que uma aula possa ser boa mesmo estando polarizada - sendo estes pólos o professor e os alunos. De um lado o professor, requer-se primeiramente que ele conheça o assunto a ser transmitido. Além disso, que tenha uma elaboração pessoal a respeito do mesmo de modo a não simplesmente repetir textos, que poderiam, com maior economia de tempo e esforço, serem lidos em casa pelos alunos. Também, requer-se que goste do tema que ensina e que, por outro lado, aprecie o fato e o ato de transmiti-lo, sem o quê o maior erudito pode tornar-se um pedante enfadado, comprometendo a qualidade de aula. Do lado dos alunos, requer-se, primeiramente, que estejam na aula por seu próprio desejo, conhecimento de causa, tanto o professor, como o tema e o enquadre da situação de ensino, com conhecimento, também, há que se dizer, das opções. Outra condição, que supõe parcialmente à anterior, é que os alunos reúnam condições, em termos de conhecimentos prévios e de maturidade pessoal, de acompanhar satisfatoriamente o curso do ensino. Uma outra ordem de condições reside nas relações que se estabelecem, em aula. Uma forma de organização que se suportasse e tolerasse as diferenças individuais - entre os alunos e de cada um desses para com o professor, já que os estabelecemos como pólos - pólos - evitaria a necessidade de uma homogeneidade ou de homogeneização, permitindo um crescimento pela confrontação e elaboração conjunta de posições conflitantes.

\section{Sujeito 7}

Um professor que, pasmem, saiba, isso mesmo, saiba a matéria que está dando. Que esta mesma matéria esteja de algum modo ligada ao curso que o aluno participa. Alunos que saibam suportar suas ignorâncias e que tenham claro para que diabos estão estudando aquele tema, e até tenham optado por estudá-lo. Já que o professor sabe porque está lá e o que vai dar a aula não necessita ser seminário. É simples, o professor tenta passar sua leitura do tema e como ele sabe, e quem sabe, sabe que nem tudo sabe, não pretende que ninguém concorde com ele. Mesmo assim brinca de articular este saber porque ele, o professor, gosta tanto do que faz como tem desejo para transmissão. Este mesmo professor não só transmite o assunto que domina, ele está inserido na efetiva aplicação deste conhecimento, ele é um profissional deste antes de ser um professor. $\mathrm{O}$ aluno não fez o segundo grau no Brasil. $\mathrm{O}$ aluno até se interessa por ramos de conhecimento, que de nenhuma forma pragmática ele vá usar. $\mathrm{O}$ aluno em vários campos é autodidata, enfim, o aluno tem um trânsito pela cultura. O desejo que move o aluno é o dele. A Universidade é Federal e logo o ensino é gratuito, afinal porque merda o governo nos suga impostos.

\section{Sujeito 8}

A "boa aula" é aquela em que eu já sei alguma coisa do assunto a ser tratado. Para mim isto é fundamental, se nos primeiros 15 minutos da aula só me são apresentadas novidades, dificilmente conseguirei retomar atenção, e a dispersão será a norma. Por outro lado, a aula deve suscitar o debate. A polêmica ou se for "necessariamente expositiva" pelo menos levantar dúvidas. A pessoa que estiver ministrando esta aula deve ser um conhecedor do assunto a ser tratado, deve trazer subsídios ao debate, contribuições diferenciadas dos "assistentes da aula" no sentido de globalizar aquilo que vai sendo exposto. Para mim as respostas dadas em aula sempre devem vir em bloco. De resto uma boa aula não deve ser ministrada no prédio do "Ciclo Básico" do Campus Médico desta Universidade, sob pena de deixar de ser uma boa aula, pois este prédio é simplesmente insuportável e inconfortável.

\section{Sujeito 9}

Uma boa aula de psicologia não teria professor, já que os temas deste campo são inesgotáveis. Haveria tão so- 
mente alunos dos mais diversos graus de conhecimento, os mais experientes questionando os novatos sobre aspectos não percebidos por estes, que, por sua vez, instigariam aqueles a revisarem criticamente seus conhecimentos mais fundamentais, simplicidade não superficial a profundidade não esotérica, de modos que o resultado fosse um aperfeiçoamento integrativo das compreensões de todos e de cada um. As "aulas" seriam gravadas em vídeo para sua revisão pelos presentes e a atualização pelos ausentes (o que seria buscado sem exceção, espontaneamente), e estes nunca se dirigiriam a seguinte desinformados $\mathrm{da}(\mathrm{s})$ precedente(s). Os estudantes teriam amplo tempo disponível para consultas e debates paralelos, possíveis inclusive, através de um eficiente sistema de comunicação videofônico. Não haveria formatura, mas cada estudantes seria sempre, simultaneamente, um trabalhador, incumbido de tarefas de acordo com sua competência até então adquirida. Quanto a “aula”, propriamente dita, realizar-se-ia num local de preferência da maioria dos presentes que estaria sempre disponível fosse num jardim gramado incrustado num pequeno vale acusticamente, ou uma confortável sala de tamanho apropriado ao grupo, também com perfeita acústica, e com acesso imediato a uma biblioteca onde nunca faltariam as obras procuradas. Os participantes teriam invariavelmente ávido interesse pelo assunto tratado, participassem ativamente das discussões ou apenas apreciassem silenciosamente, e todos seriam treinados para a dinâmica dos debates, de maneira que não houvesse confusões evitáveis, e as raras que acontecessem seriam prontamente coordenadas por um sistema eletrônico de inscrições (limite de tempo não haveria, pois todos seriam suficientemente educados para não abusar e suficientemente tolerantes para conceder "apartes" devidamente sinalizados). Quando solicitados, os mais experientes preparariam palestras, e para estes e para os debates mais importantes, contraria-se com um eficiente corpo de taquígrafos e datilógrafos, que serviriam imediatamente redações e sinopses dos trabalhos, a fim de dinamizá-los e oferecer pronta visão global aos seus participantes.

William Barbosa Gomes - Graduação em Psicologia pela Universidade Católica de Pernambuco (1971), Mestrado em Reabilitação Psicológica pelo Southern Illinois University Carbondale (1980) e Doutorado Interdisciplinar em Higher Education pelo Southern Illinois University Carbondale (1983). Atualmente é Professor Adjunto da Universidade Federal do Rio Grande do Sul. Tem experiência na área de Psicologia, com ênfase em Desenvolvimento Social e da Personalidade, atuando principalmente nos seguintes temas: história da psicologia, epistemologia, fenomenologia, e efetividade psicoterápica. Endereço para correspondência: Instituto de Psicologia - UFRGS, Rua Ramiro Barcelos 2600, 90035-003, Porto Alegre (RS). E-mail: gomesw@ufrgs.br. 